\title{
HEIDUK, Christoph, HÖFERT, Almut, ULRICHS, Cord, Krieg und Verbrechen nach spätmittelalterlichen Chroniken
}

\section{Pierre Monnet}

\section{OpenEdition}

\section{Journals}

Édition électronique

URL : http://journals.openedition.org/ifha/1361

DOI : 10.4000/ifha.1361

ISSN : 2198-8943

Éditeur

IFRA - Institut franco-allemand (sciences historiques et sociales)

\section{Référence électronique}

Pierre Monnet, « HEIDUK, Christoph, HÖFERT, Almut, ULRICHS, Cord, Krieg und Verbrechen nach spätmittelalterlichen Chroniken », Revue de l'IFHA [En ligne], Date de recension, mis en ligne le 01 janvier 1999, consulté le 22 septembre 2020. URL : http://journals.openedition.org/ifha/1361 ; DOI : https:// doi.org/10.4000/ifha.1361

Ce document a été généré automatiquement le 22 septembre 2020.

(CIFHA 


\title{
HEIDUK, Christoph, HÖFERT, Almut, ULRICHS, Cord, Krieg und Verbrechen nach spätmittelalterlichen Chroniken
}

\author{
Pierre Monnet
}

1 Cette collection était déjà connue pour avoir édité deux ouvrages consacrés à l'analyse et à l'interprétation des chroniques allemandes de la fin du Moyen Âge (Andrea DIRSCH-WEIGAND, Stadt und Fürst in der Chronistik des Spätmittelalters, 1991 et Rolf SPRANDEL, Chronisten als Zeitzeugen, 1994). Le présent volume regroupe trois contributions attachées à l'étude de la guerre et du crime dans les chroniques du Moyen Âge tardif. La première, prenant appui sur des chroniques de Silésie et de Lusace, en particulier de la ville de Breslau, tente de comprendre comment les chroniqueurs ont rendu compte de la naissance d'un droit public entre législation urbaine et législation territoriale. L'auteur abouti à la conclusion selon laquelle les rédacteurs de sources narratives non seulement savaient décrypter les textes normatifs (appartenant aux couches dirigeantes des villes, ils en étaient parfois les auteurs), mais s'entendaient également à restituer le sens de comportements déclenchés par le respect ou le non-respect des procédures judiciaires. Ils étaient également sensibles aux effets de nivellement des conditions au regard du droit, criminel en particulier. Ils ont compris que la criminalisation des faides par les autorités urbaines servait à souder l'unanimisme citadin autant qu'à renforcer les institutions de la ville. De la sorte, par leurs œuvres, ils contribuèrent à répandre une conception de la justice mettant en question la résistance de la violence face au progrès du droit. En conclusion, l'auteur note de manière pertinente que c'est finalement sur les prérogatives de l'Église et les privilèges du droit canon que les chroniqueurs sont le plus partagé, notamment sur les questions de l'asile, de l'hérésie et de la sorcellerie, trois thèmes érigés en indicateurs d'une sensibilité qui resurgira tout au long de la Réforme dans les pays allemands.

2 La seconde contribution prend pour thème l'étude de la guerre vue à travers le prisme subjectif des journaux, mémoires et chroniques publiques et privées rédigés par le patriciat et la noblesse du Sud de l'Allemagne: Francfort (les Rohrbach), Nuremberg 
(Ulman Stromer, Berthold et Endres Tucher, Nikolaus Muffel) et le cas de Georg von Ehingen. Pour l'auteur, l'analyse du discours guerrier développé par Georg von Ehingen dans son célèbre Raisen nach der Ritterschaft avait avant tout pour objectif de montrer que les élites des villes d'Empire, Francfort et Nuremberg en tête, n'ont pas intégré le discours courtois et chevaleresque mais, en dépit des manifestations festives d'une guerre théâtralisée en ville (concours de tirs, tournois, batailles...), ont conservé de la guerre l'image d'un horizon permanent, réel et objectif face auquel les méthodes éprouvées de finance et d'administration devaient être employées. Ainsi, c'est moins dans sa capacité militaire et stratégique que la ville, d'après les élites qui écrivent à son propos, aurait forgé son identité, que plutôt dans sa capacité à la circonscrire et à la combattre par les armes proprement citadines de la bonne gestion et du bon gouvernement. C'est sans doute la raison pour laquelle les chroniqueurs de ces villes n'ont pas développé de discours critique envers la guerre et ses méfaits, mais seulement vu en elle un problème à régler au même titre qu'une cherté, une épidémie ou un incendie: la ville était bien devenue, sous leur plume, un espace d'administration et de paix sans clercs ni chevaliers...

3 La troisième contribution s'intéresse à la vision de la guerre développée par le rédacteur anonyme, secrétaire du Grand Maître des Teutoniques à la Marienburg, de la guerre dite de Treize Ans survenue entre l'Ordre des Teutoniques et la ligue prusse entre 1454 et 1466 (seconde paix de Torun). C'est à bon droit que l'on peut voir dans cette œuvre l'une des premières monographies guerrières. Mais l'intéressant tient à ce que cette relation qui commence par décrire le conflit comme une faide, certes de grande ampleur mais point extraordinaire, arrive peu à peu à en faire un traité construit sur les causes, le déroulement et l'issue d'une guerre organisée et motivée mettant aux prises non seulement des hommes, mais aussi des territoires et des systèmes d'organisation politique. Il ne faudrait pas pour autant en conclure à la relation d'une guerre »moderne« ou »prénationale«, une dimension qui fait totalement défaut dans le récit. Il importe seulement de souligner combien des principes généraux sont ici opposés: le prince contre les villes, le droit contre la force, une autorité seigneuriale contre une ligue provisoire ou en tout cas limitée, l'Ordre religieux des Teutoniques qui remplit une mission contre une assemblée hétéroclite seulement occupée à défendre des intérêts. L'exemple montre ainsi quel degré de conceptualisation et quel potentiel de justification, au milieu du XVe s., l'écriture de l'histoire, à côté de la chronistique traditionnelle de l'Ordre Teutonique, a déjà atteint 